UDC: 821.134.2.09-1 Alberti R.

821.134.2(83).09-1 Neruda P.

821.134.2(82).09-1 Girondo O.

DOI: https://doi.org/10.18485/beoiber.2020.4.1.3

\author{
Isidora Kalović ${ }^{1}$
}

Doctoranda en la Universidad de Belgrado

Serbia

\title{
LA IMAGEN DE LA GUERRA CIVIL ESPAÑOLA EN LA POESÍA VANGUARDISTA: EL CASO DE RAFAEL ALBERTI, PABLO NERUDA Y OLIVERIO GIRONDO ${ }^{2}$
}

\begin{abstract}
Resumen
La Guerra Civil española es un suceso que se convirtió en tema de muchas obras vanguardistas. Obviamente, las vidas mismas de poetas de España cambiaron mucho por el suceso mencionado, incluso la mayoría de ellos siguió su vida en el exilio. Empero, los poetas latinoamericanos se encontraron afectados también. Tratando de responder a la pregunta: ¿Cuál es la razón de esto?, comentaremos las influencias a los poetas latinoamericanos para elaborar este tema. Se abre, entonces, la cuestión de la estrecha relación entre la lengua y la identidad, porque se supone que la lengua es el enlace más fuerte e importante entre los poetas latinoamericanos y su "patria europea" - España. En los casos de tres poetas, de España, Chile y Argentina, analizaremos las semejanzas y las diferencias entre sus visiones de dicha guerra. En el trabajo nos centraremos en los poemas «Galope» de Alberti, «Explico algunas cosas» de Neruda y en el relato de Girondo llamado «Interlunio». La reiteración de este tema en las obras vanguardistas exige que nos demos cuenta de su importancia y el análisis comparativo ofrece una distinción de los aspectos universales y locales de su elaboración. Lo dicho es, al mismo tiempo, el objetivo de nuestro trabajo: acentuar la importancia del tema de la guerra que sucedió en España y analizar su elaboración por parte de tres poetas cuidadosamente seleccionados.

Palabras clave: Guerra Civil española, Rafael Alberti, Pablo Neruda, Oliverio Girondo, poema.

1 isidorakalovic@gmail.com

2 La idea principal de este trabajo fue presentada en el I Coloquio Internacional «1927-2017: Herencias, balances, traducciones y relecturas de la Vanguardia Internacional» en septiembre de 2017 en Roma.
\end{abstract}




\title{
THE IMAGE OF THE SPANISH CIVIL WAR IN AVANT-GARDE POETRY: THE CASE OF RAFAEL ALBERTI, PABLO NERUDA AND OLIVERIO GIRONDO
}

\begin{abstract}
Summary
The Spanish Civil War is an event that became the subject of many avant-garde works. The lives of poets in Spain were affected by the aforementioned event, most of the Spanish poets continued their life in exile. However, Latin American poets were also affected. Trying to answer the question: What is the reason for this?, we will comment on the influences on Latin American poets to elaborate on this theme. Then, the question of the close relationship between language and identity opens up because language is supposed to be the strongest and most important link between Latin American poets and their "European homeland" - Spain. In the cases of three poets, from Spain, Chile, and Argentina, we will analyze the similarities and differences between their visions of this war. In the paper, we will focus on the poem "Galope" by Alberti, "Explico algunas cosas" by Neruda, and Girondo's story called "Interlunio". The reiteration of this theme in avant-garde works demands that we realize its importance and the comparative analysis offers a distinction between the universal and local aspects of its elaboration. That is at the same time the objective of our work - to emphasize the importance of the theme of the war that happened in Spain and to analyze its elaboration by three carefully selected poets.
\end{abstract}

Keywords: The Spanish Civil War, Rafael Alberti, Pablo Neruda, Oliverio Girondo, poem.

La Guerra Civil española (1936-1939) es el suceso histórico que vinculó temáticamente la poesía de ambos lados del Atlántico y que dejó una importante huella en las obras de poetas vanguardistas. Se trata de un evento crucial en la historia de la España del siglo XX, un hecho importantísimo para la historia europea de esa época también. Por eso, no sorprende la abundancia de obras literarias que tratan este tema, ya que la guerra misma es un acontecimiento que cambia las vidas de las personas inmiscuidas y si nos referimos a una guerra civil, toda la nación queda afectada. Parece que los ejemplos de temática bélica se pueden encontrar desgraciadamente en cada literatura nacional, tenemos otro ejemplo en la literatura, incluso toda la obra artística serbia que desde hace más de dos décadas no para de tratar el tema de la guerra en la antigua Yugoslavia. ${ }^{3}$ Los rastros que quedan después de estos terribles acaecimientos duran mucho y obviamente afectan la obra artística.

En este artículo analizamos la obra del poeta español, Rafael Alberti, del poeta chileno, Pablo Neruda y del poeta argentino, Oliverio Girondo. Cada escritor representa diferente grado de relación con España y con la guerra de los años 30. Además, cada uno escribe sobre la Guerra Civil española de diferente manera y la incluye en su obra en diferente grado y por razones distintas. Rafael Alberti es el representante más cercano a

3 Películas: Ubistvo s predumišljajem (1995), Lepa sela lepo gore (1996), Spasitelj (1998), Ničija zemlja (2001), Turneja (2008), Krugovi (2013), etc.

Libros: Bila jednom jedna zemlja de Dušan Kovačević (1995), Ko je ubio Katarinu de Vuk Drašković (2017), etc. 
la Guerra Civil española. Pablo Neruda es un representante hispanoamericano que tuvo una experiencia personal de la situación bélica española. Al final, Oliverio Girondo representa a un escritor hispanoamericano que visitó España en el año 1923 y hasta 1948 no viajó a Europa, de hecho, no tuvo una experiencia próxima del acontecimiento mencionado. No es nada raro que un poeta andaluz, miembro del partido Comunista de España que se exilió tras la Guerra Civil española, Rafael Alberti, escribiera poemas sobre el acontecimiento mencionado, pero queda la cuestión ¿por qué se extiende el interés por este tema a América Latina, o sea a la literatura hispanoamericana?

Neruda no es el único poeta vanguardista hispanoamericano que escribió sobre esta etapa para que podamos decir que es una excepción debida a su itinerario personal o vital, hay muchos otros escritores que trataron este tema, tal y como el ya mencionado Oliverio Girondo de Argentina, César Vallejo de Perú, Vicente Huidobro de Chile, Octavio Paz de México, etc. Hay una base que acerca a los hispanoamericanos a los sucesos que pasan en España y esa base, según nuestra opinión, es la lengua misma, que vincula estrechamente España y sus antiguas colonias. La lengua española en la que escriben sus versos o frases los autores hispanoamericanos, forma parte de su identidad y por eso les afecta más lo que pasa en España que en otros sitios del mundo. Entonces la íntima vincu-lación entre el lenguaje y la identidad es, según nuestra opinión, la razón principal de observar y sentir la Guerra Civil española tan cercana incluso de la otra parte del Atlántico. Entre diferentes observaciones sobre la lengua y la identidad destacamos la de Sabine Ulibarrí del año 1973:

In the beginning was the Word. And the Word was made flesh. It was so in the beginning and it is so today. The language, the Word, carries within it the history, the culture, the traditions, the very life of a people, the flesh. Language is the people. We cannot even conceive of a people without a language, or a language without a people. The two are one and the same. To know one is to know the other. ${ }^{4}$ (Ulibarrí apud Roberts 2009: 47)

La lengua define lo que somos, nos une y habilita el mejor entendimiento de una cultura, tradición, historia e incluso, toda la nación. Por eso, hipotéticamente, no existe ningún obstáculo que complique el entendimiento de los sucesos que pasan en España por parte de los hispanoamericanos y viceversa. Consideramos la lengua como la razón principal del gran interés de los poetas hispanoamericanos por este tema.

Nosotros, además, vamos a entrar un poco en el proceso de la creación literaria y encontramos la descripción del proceso de la creación narrativa que Vargas Llosa (1971: 87) dio en su tesis doctoral García Márquez: historia de un deicidio que incluye la teoría de

${ }^{4}$ «En el principio era la Palabra. Y la Palabra se hizo carne. Así era al principio y así es hoy. El lenguaje, la Palabra, lleva dentro de sí la historia, la cultura, las tradiciones, la vida misma de un pueblo, la carne. El lenguaje es la gente. Ni siquiera podemos concebir un pueblo sin un idioma, o un idioma sin un pueblo. Los dos son uno y lo mismo. Conocer uno es conocer al otro.» (Traducción hecha por la autora del artículo.) 
los demonios de un novelista. Esta teoría se puede extender a toda la creación artística y la encontramos incluso más conveniente para los poemas y relatos que tratan un tema bélico y representan la actitud íntima del escritor. Algunas partes de dicha teoría nos pueden servir para tratar de contestar a la pregunta principal. En la teoría vargasllosiana existen tres tipos de demonios que puedan provocar el acto de construir una obra artística: personales, históricos y culturales. ¿Por qué son importantes los demonios de un escritor? Porque, según Vargas Llosa:

El proceso de la creación narrativa es la transformación del "demonio" en "tema" [...] Un escritor no elige sus temas, los temas lo eligen a él. [...] Un hombre no elige sus "demonios": le ocurren ciertas cosas, algunas lo hieren tanto que lo llevan, locamente, a negar la realidad y a querer reemplazarla. (Vargas Llosa 1971: 87, 94)

Los demonios personales pueden ser «experiencias que afectaron específicamente a la persona del suplantador de Dios», o sea, al escritor, «los demonios históricos pueden ser sucesos que afectaron o patrimonio de la sociedad del escritor o de su tiempo» y los demonios culturales pueden ser «experiencias indirectas de la realidad real, reflejadas en mitología, el arte o la literatura» (Vargas Llosa 1971: 87-94). Según Vargas Llosa (1993: 150), un escritor normalmente transforma su experiencia personal a la obra ficticia, por lo cual considera que la experiencia o cualquier otro demonio del escritor representa la base de una obra artística. Por lo dicho, los demonios que provocan la creación artística, siempre traen consigo una parte de escritor en la obra artística.

Hablando de Rafael Alberti, notamos que su exilio es obviamente un demonio personal y la guerra misma es el demonio histórico, según la teoría de Vargas Llosa. Considerando el caso de Pablo Neruda, veremos que en su poema «Explico algunas cosas», el poeta representa su residencia en Madrid donde vivió a la hora de desempeñar su función de cónsul desde 1934, la denomina «mi casa» y a su amigo Federico García Lorca lo designa como «mi hermano»:

\section{Mi casa era llamada}

la casa de las flores, porque por todas partes

estallaban geranios: era

una bella casa

con perros y chiquillos.

Raúl, te acuerdas?

Te acuerdas, Rafael?

Federico, te acuerdas

debajo de la tierra,

te acuerdas de mi casa con balcones en donde

la luz de junio ahogaba flores en tu boca?

Hermano, hermano (Neruda 2011; lo subrayado es nuestro) 
Y más allá:

\author{
Generales \\ traidores: \\ mirad mi casa muerta, \\ mirad España rota (Neruda 2011; lo subrayado es nuestro)
}

Vemos que Neruda habla sobre aspectos personales de la Guerra Civil española, que le afectan personalmente a él. Además, el suceso histórico marcó esta época de su vida ideológica y personalmente y lo podemos considerar como un demonio histórico también. Girondo, distanciado, escribe sobre la guerra afectado por los demonios históricos y culturales, porque suponemos que el contacto con los textos ya escritos creó una parte de su imagen del hecho. De lo dicho, podemos notar que los escritores hispanoamericanos pueden sentir lo que pasa en España como su demonio personal, histórico o cultural porque la literatura que tuvo mayor influencia sobre los escritores hispanoamericanos era española. Aunque Girondo era comprometido con «el lenguaje y literatura americanos» y apoyaba la liberación de América Latina de todos los impuestos europeos (Rizzo-Vast 2001: 118), la lengua es el vínculo más fuerte para despertar su interés por este tema.

Otro vínculo importante para este tema y autores que analizamos, es la ideología. Rafael Alberti era republicano, elegido diputado por el Partido Comunista de España. Pablo Neruda y Oliverio Girondo tuvieron la misma actitud ideológica. Pablo Neruda participó en la vida política más que Girondo. Las voces literarias de Pablo Neruda y César Vallejo contribuyeron a los esfuerzos republicanos ya que los intelectuales hispanoamericanos miraban más allá de la España conquistadora y del resultante colonialismo cultural y apoyaron al primer intento de «hispanizar» el marxismo (Zee 2011). Los tres poetas que tratan este tema durante la guerra escriben textos comprometidos. El arte se convierte en una herramienta para influir a la sociedad:

El arte se ponía al servicio de la sociedad y escritores de muy distintas nacionalidades se aunaban en el sueño de restablecer las libertades usurpadas. Los escritores hispanoamericanos, por su identidad lingüística y proximidad, podríamos llamar "visceral", hacia el pueblo español, tampoco se mantendrían al margen. (Vázquez 1996: 529)

Podemos decir que los poemas de Alberti y Neruda son más comprometidos que el relato de Girondo en el que el escritor da una imagen triste de Europa y se lamenta por los sucesos acontecidos. En el caso de Alberti que recitó este poema a los soldados, no hay que explicar el compromiso literario. En el caso de Pablo Neruda, concretamente en su 
poema «Explico algunas cosas» usa la Guerra Civil española no solamente para condenarla, sino también para explicar el cambio de su poesía:

PREGUNTARÉIS: Y dónde están las lilas?

Y la metafísica cubierta de amapolas?

Y la lluvia que a menudo golpeaba

sus palabras llenándolas

de agujeros y pájaros? (Neruda 2011)

La Guerra Civil española transformó su poesía y su existencia (Amorós 2015). Se puede notar una transición de la poesía surrealista a una poesía de lenguaje coloquial e inmediato con la misión didáctica y propagandística (Operé 2006: 53). Deja el aspecto individual de su poesía y escribe para la sociedad, porque según él, la poesía es la parte de la solución (Caballero, Migliore 2014: 294). Además, en vez de tratar temas bellos, le ocupan temas sangrientos:

Preguntaréis por qué su poesía

no nos habla del sueño, de las hojas,

de los grandes volcanes de su país natal?

Venid a ver la sangre por las calles,

venid a ver

la sangre por las calles,

venid a ver la sangre

por las calles! (Neruda 2011)

El cambio de su poesía hacia la literatura comprometida se refleja en todo el poemario sobre la Guerra Civil:

España en el corazón será el reflejo de un poeta indignado que reaccione ante la guerra agresivamente. Consciente del poder de la palabra, y en base a sus experiencias biográficas, concibirá su poesía como oficio. La utilidad de la poesía, concebida como "instrumento", le lleva, pues, a depurar su lenguaje poético hasta alcanzar las cotas de lo que él llama una "poesía impura". (Vázquez 1996: 535)

Otra pregunta importante para este tema es ¿qué y cómo escribieron los escritores sobre la Guerra Civil española? En el trabajo nos centraremos en los poemas «Galope» de Alberti, «Explico algunas cosas» de Neruda y en el relato de Girondo llamado «Interlunio». La imagen más llamativa después de leer estas tres obras es la imagen de la muerte, lo que es normal porque la muerte es algo cotidiano, pero lo más terrible en época de guerra. Es importante acentuar que estos tres escritores no eligieron hablar sobre el miedo, sobre la pobreza, o sobre algunos otros problemas presentes durante la guerra, sino sobre la muerte. 
Como hemos mencionado, Rafael Alberti recitó el poema «Galope» o «A galopar» a los soldados republicanos durante la Guerra y él da una imagen diferente de la muerte que otros dos escritores. Según él, la muerte es nada, no hay que tener miedo de la muerte, hay que luchar, «a galopar / hasta enterrarlos en la mar» (Alberti 1990: 31). La muerte acentúa la importancia de la lucha contra el fascismo. En este contexto, la vida tiene sentido solamente si no renunciamos a la lucha, si no nos rendimos.

Pablo Neruda pregunta a García Lorca muerto sobre su casa y después dice «mi casa muerta». Está claro que la casa vacía, como objeto de piedra, de ladrillos, no puede estar muerta, puede estar destruida. Pero está muerta porque ha muerto el alma, el espíritu, una persona muy importante, algo que hacía que la casa viviera. La muerte, presentada por la sangre derramada en las calles madrileñas, despierta la responsabilidad de Neruda como escritor (Torre Barrión 1999: 64). De hecho, él tiene que describir el horror de la guerra, para dejar la huella de sucesos sangrientos.

Oliverio Girondo escribe su relato más distanciado, compara Europa con un cementerio, enfatizando la muerte de personas importantes:

La tierra ya no da más. Es demasiado vieja. Está llena de muertos. Y lo que es peor aún, de muertos importantes. En vano se trata de eludirlos. Se tropieza con ellos en todas partes. No hay un umbral, un picaporte que no hayan desgastado. Se vive bajo los mismos techos donde vivieron y donde han muerto. Y por mucho que nos repugne - ¡no queda otro remedio! - hay que repetir sus gestos, sus palabras, sus actitudes. (Girondo 1937: 21)

En el relato de Girondo podemos notar la repetición de la palabra muerte para enfatizar la rabia, la insatisfacción, el dolor por los sucesos que pasan. Él también fue amigo de García Lorca, siendo éste una de las personas importantes a los que alude. Esta parece ser la única relación personal con la Guerra Civil de Girondo, por lo que destaca la muerte como el aspecto central de la Guerra Civil.

Obviamente, se pueden notar muchas similitudes estilísticas entre los poemas de Neruda y Alberti. Como Girondo escribe un relato, su texto se diferencia más, porque se aleja de la escritura poética. Tanto Neruda como Alberti usan apostrofas, pero Neruda se dirige a sus amigos poetas, sus «hermanos», a los lectores y a los «generales traidores». Alberti, por otra parte, apostrofa al pueblo, a los soldados: «Galopa, caballo cuatralbo, / jinete del pueblo» (Alberti 1990: 31). Podemos concluir que la diferencia más grande entre los poemas de Neruda y Alberti son los destinatarios. Por una parte, Neruda dirige sus versos a los lectores y se nota la intimidad en el poema, se trata de una confesión íntima del escritor: "Os voy a contar todo lo que me pasa» (Neruda 2011). Alberti, por otro lado, escribe casi un himno que tiene que afectar a todos los hombres que participan en la guerra en el bando republicano. En vez del tono íntimo de Neruda, el poema de Alberti tiene un tono solemne y grandilocuente. Sin embargo, el objetivo testimonial está presente en ambos autores: 
Los poemas de Neruda y Alberti le hablan a sus contemporáneos, pero también responden de forma indirecta a estas preguntas, luchando contra una política del olvido convirtiendo sus textos en testimonios que mantienen la memoria colectiva enraizada, conectada a su historia. (Enjuto Rangel 2010: 349)

\section{Conclusión}

En conclusión, podemos decir que la Guerra Civil española representa un encuentro temático importante de los poetas españoles e hispanoamericanos de esta época:

El estallido de la guerra fue para Neruda y para todos los escritores e intelectuales hispanoamericanos, el reencuentro con la patria-madre: España. La guerra ha restablecido el vínculo sanguíneo. En la poesía de Neruda, de Vallejo, y de muchos otros, España recupera su símbolo de la Madre, pero una madre dolorida cuyos gritos se oyen en todo el continente americano. Como hijo compasivo, Neruda viene a auxilio de España. (Mbaye 2006)

En el trabajo hemos tratado el tema de la relación entre la identidad y la lengua y hemos concluido que la lengua es la base más fuerte para el interés sobre este tema de los escritores hispanoamericanos. Sin embargo, la lengua castellana no es la única cosa que provoca este interés, también tenemos que mencionar la misma ideología política de los tres autores, que es muy importante para su compromiso literario. Además, hemos visto que la teoría de Vargas Llosa sobre la creación artística se puede aplicar a la creación literaria de Alberti, Neruda y Girondo. Cada escritor tenía razones diferentes a la hora de elaboración de este tema. A Neruda le afectaron los «demonios» personales e históricos, según dicha teoría, a Girondo los históricos y culturales y al final, para Alberti la necesidad de tratar este tema era un impulso natural de expresar el dolor por su patria, de hecho, hablamos sobre los «demonios» personales e históricos.

Como Alberti y Neruda escriben sobre algunas experiencias personales, no sorprende que en sus poemas encontremos una imagen subjetiva, intensa y perturbadora de la Guerra Civil y una visión de España en ella llena de llanto y desesperación. En el relato de 1937, Girondo poniéndose a distancia, por otra parte, nos da una imagen poderosa de Europa funeral. Los poetas de tres diferentes países se encuentran unidos por su reflexión sobre el mismo asunto que elaboraron de maneras distintas con las particularidades estilísticas propias de los autores. Sin embargo, en los textos citados encontramos muchos rasgos similares que ya hemos comentado en el trabajo, tales como la acentuación de imagen de la muerte y el compromiso literario. La Guerra Civil fue un 
evento muy importante tanto para la historia como para la literatura, porque «transformó poesía latinoamericana y española, en lo que podríamos llamar una poética trasnacional, y específicamente trasatlántica» (Enjuto Rangel 2010: 346).

\section{BIBLIOGRAFÍA}

Alberti, Rafael. «Galope». Antología comentada. Madrid: Ediciones de la Torre, 1990. 31. Impreso.

Amorós, Mario. Neruda: el príncipe de los poetas. Ediciones B: e-book, 2015. Web. 15.01.2018. Caballero, Bárbara, y María José Migliore. «Testimonios poéticos de la Guerra Civil Española: los casos de Neruda y Vallejo». Actas del VI Congreso Internacional de Letras: Transformaciones culturales. Debates de la teoría, la crítica y la lingüística. Dirigidas por Miguel Vedda y Juan Pablo Moris. Buenos Aires: Universidad de Buenos Aires, Facultad de Filosofía y Letras, 2014. 292-299. Impreso.

Enjuto Rangel, Cecilia. «Madrid en ruinas: la poética trasatlántica de Neruda y Alberti». INTI 71-72 (2010): 345-356. Web. 03.06.2019.

Girondo, Oliverio. Interlunio. Buenos Aires: Sur, 1937. Impreso.

Mbaye, Djibril. «Neruda y la guerra civil española», Crítica.cl, 2006. Web. 15.01.2018.

Neruda, Pablo. «Explico algunas cosas». Antología poética. Madrid: Espasa, 2011. E-libro.

Operé, Fernando. «Diálogo entre dos mundos: la España de Pablo Neruda». Cuadernos de Literatura 10.20 (2006): 53-66. Web. 03.06.2019.

Rizzo-Vast, Patricio. «Paisaje e ideología en Campo nuestro de Oliverio Girondo». Revista Iberoamericana LXVII.194-195 (2001): 105-120. Web. 03.06.2019.

Roberts, Shelley. Remaining and Becoming: Cultural Crosscurrents in an Hispano School. London: Routledge, 2001. Print.

Torre Barrión, Arcelia de la. «La guerra civil española en los ojos de Pablo Neruda: España en el corazón». La Colmena 21 (1999): 59-65. Web. 03.06.2019.

Vargas Llosa, Mario. García Márquez: historia de un deicidio. Barcelona: Barral Editores, 1971. Impreso.

Vázquez, María. «Hispanoamérica y la Guerra Civil española vista a través de dos de sus poetas: César Vallejo y Pablo Neruda». Aldaba 28 (1996): 529-542. Web. 03.06.2019.

Zee, Linda. «La Guerra Civil española en la obra de César Vallejo y Pablo Neruda». Crítica.cl, 2001. Web. 15.01.2018. 